\title{
Optimization of Flotation Process of Zinc Oxide Ore by Response Surface Methodology
}

\author{
Mingxiao $\mathrm{Li}^{1, \mathrm{a}}$, Fengxiang Liu ${ }^{1, \mathrm{~b}}$, Xuewu Wang ${ }^{1, \mathrm{c}}$, Gang Wang ${ }^{1, \mathrm{~d}}$ \\ ${ }^{1}$ Brigade 209 of Nuclear Industry of Yunnan Province, Kunming, Yunnan 650032, China \\ amx816@126.com, byn209liufx@hotmail.com, cwxw209@163.com, ${ }^{\mathrm{d}}$ wanggang@yn209.com
}

Keywords: Response surface methodology; Floatability; Optimization; Zinc oxide ore.

\begin{abstract}
According to the test results, the flotation process parameters of refractory zinc oxide ore will be optimized by the response surface methodology in this paper. The regression model between Zn recovery and sodium sulfide concentration, depressant(F1) concentration and sodium carbonate concentration was established. It can be known that the model is highly significant and test error is very small, and the concentration of sodium sulfide has great influence to the recovery of $\mathrm{Zn}$ concentrate. The verification tests results show that the model is reliable and can predict accurately the zinc recovery. It can be concluded that the optimizing process parameters are sodium sulfide $7500 \mathrm{~g} / \mathrm{t}$, depressant concentration $1050 \mathrm{~g} / \mathrm{t}$, and sodium carbonate concentration $2200 \mathrm{~g} / \mathrm{t}$, which can provide the technical basis for the comprehensive utilization of low grade refractory zinc oxide ore.
\end{abstract}

\section{Introduction}

As the primary source of zinc, natural sulfide ores are steadily getting depleted and for future demand, there is an obvious recognition that the recovery of zinc from oxidized ores is an alternative. It is well known that the main processing methods are flotation, acid leaching and ammonia leaching for refractory zinc oxide ore which contains high-content alkaline gangues [1]. However, if the ore is treated just by flotation, its recovery is very low due to the poor processing efficiency of zinc oxide. In this case, the massive zinc metal are lost in the slime resulting in waste of resources. If the raw ore is directly processed by hydrometallurgy, high-content alkaline gangues will consume a large amount of acid leading to very high beneficiation cost [2]. The disadvantages of ammonia leaching process are serious environmental pollution, high energy consumption and equipment investment [3]. A new dressing-metallurgy combination process can avoid effectively the above problems. In recent years, the rapid development of acid leaching-extraction-electrodeposition technology, greatly promote the zinc hydrometallurgical process [3-5]. Nevertheless, most of zinc oxide ore has the characteristics of low grade, high oxidation rate and high-content alkaline gangues, is inappropriate to adopt directly the method of acid leaching treatment, require pretreatment of flotation and enrichment of zinc concentrate grade to more than $15 \%$ [6]. Under the premise of ensuring zinc recovery rate, removing the calcium and magnesium alkaline gangues.

Response surface methodology is the product of combining mathematical method and statistical method, with the scientific design and intuitive three-dimensional curved surface and contour output, product design and process optimization are the favor of the researchers. However, in terms of flotation process for refractory zinc oxide ore, the application of response surface methodology has not been reported. According to the test results and the response surface methodology, the flotation process conditions of refractory zinc oxide ore will be optimized by the author, providing the technical basis for the comprehensive utilization of low grade refractory zinc oxide ore with high-content alkaline gangues. 


\section{Experiment}

\subsection{Materials}

The samples used in this work were taken from the Lanping mine located in the west of Yunnan province, China. Complete physical, chemical and mineralogical characterization was carried out before performing the flotation tests. The chemical analysis and phase analysis results of zinc oxide sample are shown in Table 1 and Table 2, respectively. Reagents such as sodium carbonate, sodium sulfide, F1(modified depressant) and HHA (modified amine collector) were used in this investigation.

Table 1 Chemical analysis of zinc oxide sample

\begin{tabular}{rccccccc}
\hline Component & $\mathrm{Zn}$ & $\mathrm{Pb}$ & $\mathrm{Fe}$ & $\mathrm{SiO}_{2}$ & $\mathrm{CaO}$ & $\mathrm{MgO}^{2}$ & $\mathrm{Al}_{2} \mathrm{O}_{3}$ \\
\hline Content(\%) & 7.45 & 1.12 & 5.36 & 26.78 & 22.51 & 2.16 & 2.53 \\
\hline \multicolumn{7}{c}{ Table 2Phase analysis of } & zinc oxide sample \\
\hline Zinc phase analysis & Zinc carbonate & Zinc silicate & Zinc sulfide & Others & Total Zn \\
\hline Content(\%) & 3.75 & 3.14 & 0.48 & 0.08 & 7.45 \\
Distribution rate(\%) & 50.34 & 42.15 & 6.44 & 1.07 & 100.00 \\
\hline
\end{tabular}

\subsection{Experimental method and apparatus}

The flotation experiments containing two rougher were done in the XFD flotation machine and the impeller speed was $1998 \mathrm{rpm}$. Sodium carbonate with a sample of $500 \mathrm{~g}$ in weight was added into the rod mill to be ground together for $\mathrm{pH}$ adjustment and dispersing slime. Slurry containing $500 \mathrm{~g}$ ground sample was fed to flotation cell (1.5L) and the pulp density was 30\%. A 2\% F1 solution was used for depressant of gangues, and then $\mathrm{Na}_{2} \mathrm{~S}$ was added to the pulp and conditioned for $5 \mathrm{~min}$. After conditioning, $\mathrm{pH}$ reached to $10.5 \sim 11$ which was considerably suitable for adding other reagents especially collector HHA. Finally, the zinc concentrate and tailing were filtered, dried, weighed and analyzed when flotation operation were finished.

\subsection{Designs of response surface methodology}

According to the experiment principle of Box-Behnken Design, the three factors $\mathrm{Na}_{2} \mathrm{~S}$ concentration $\left(\mathrm{X}_{1}\right)$, F1 concentration $\left(\mathrm{X}_{2}\right)$ and $\mathrm{Na}_{2} \mathrm{CO}_{3}$ concentration $\left(\mathrm{X}_{3}\right)$ which influenced significantly flotation indexes were selected. Experimental design of 3 factors 3levels was carried out on the basis of single factor test. The Table3 shows the experimental factors and levels in terms of the equation $\mathrm{X}_{\mathrm{i}}=\left(\mathrm{X}_{\mathrm{i}}-\mathrm{X}_{0}\right) / \Delta \mathrm{X} . \mathrm{X}_{\mathrm{i}}$ is code value of the argument, $\mathrm{X}_{\mathrm{i}}$ is real value of the argument, $\mathrm{X}_{0}$ is real value of the argument at the test center point, $\Delta \mathrm{X}$ is change step of the argument.

Table 3 Experimental factors and levels

\begin{tabular}{ccccc}
\hline Factor & Code & & Level \\
\hline & $\mathrm{X}_{\mathrm{i}}$ & -1 & 0 & +1 \\
$\mathrm{Na}_{2} \mathrm{~S}$ & $\mathrm{X}_{1}$ & 5000 & 6500 & 8000 \\
$\begin{array}{c}\mathrm{F} 1 \\
\text { concentration(g/t) }\end{array}$ & $\mathrm{X}_{2}$ & 0 & 750 & 1500 \\
$\begin{array}{c}\mathrm{Na}_{2} \mathrm{CO} \\
\text { concentration }(\mathrm{g} / \mathrm{t})\end{array}$ & $\mathrm{X}_{3}$ & 0 & 2000 & 4000 \\
\hline
\end{tabular}

Notes: $\mathrm{x} 1=(\mathrm{X} 1-6500) / 1500 ; \mathrm{x} 2=(\mathrm{X} 2-750) / 750 ; \mathrm{x} 3=(\mathrm{X} 3-2000) / 2000$. 


\section{Results and discussion}

\subsection{Experimental results}

The recovery of $\mathrm{Zn}$ concentrate was used as the response value. According to the Box-Behnken Design, the corresponding test scheme and results are shown in Table4 in terms of the change of the three factors.

Table 4 Box-Behnken Design arrangement and the experimental data

\begin{tabular}{cccccccc}
\hline No. & \multicolumn{3}{c}{ Code } & \multicolumn{3}{c}{ Real vale } & $\begin{array}{c}\text { Recovery of Zn } \\
\text { concentrate(\%) }\end{array}$ \\
\hline & $\mathrm{x}_{1}$ & $\mathrm{x}_{2}$ & $\mathrm{x}_{3}$ & $\mathrm{X}_{1}$ & $\mathrm{X}_{2}$ & $\mathrm{X}_{3}$ & \\
1 & 0 & 0 & 0 & 6500 & 750 & 2000 & 88.76 \\
2 & 0 & 1 & -1 & 6500 & 1500 & 0 & 87.57 \\
3 & 1 & 1 & 0 & 8000 & 1500 & 2000 & 87.94 \\
4 & 0 & 1 & 1 & 6500 & 1500 & 4000 & 86.12 \\
5 & 1 & -1 & 0 & 8000 & 0 & 2000 & 88.42 \\
6 & 1 & 0 & 1 & 8000 & 750 & 4000 & 90.05 \\
7 & 0 & 0 & 0 & 6500 & 750 & 2000 & 88.76 \\
8 & 1 & 0 & -1 & 8000 & 750 & 0 & 87.58 \\
9 & 0 & -1 & -1 & 6500 & 0 & 0 & 77.08 \\
10 & 0 & -1 & 1 & 6500 & 0 & 4000 & 80.59 \\
11 & -1 & 0 & 1 & 5000 & 750 & 4000 & 71.96 \\
12 & 0 & 0 & 0 & 6500 & 750 & 2000 & 88.76 \\
13 & 0 & 0 & 0 & 6500 & 750 & 2000 & 88.76 \\
14 & 0 & 0 & 0 & 6500 & 750 & 2000 & 88.76 \\
15 & -1 & 0 & -1 & 5000 & 750 & 0 & 72.33 \\
16 & -1 & 1 & 0 & 5000 & 1500 & 2000 & 70.14 \\
17 & -1 & -1 & 0 & 5000 & 0 & 2000 & 75.13 \\
\hline
\end{tabular}

\subsection{Model establishment and significance test}

The experimental data of zinc recovery in table 4 were implemented multivariate regression fitting by using the Expert Design software. The quadratic multivariate regression equation of taking $\mathrm{Zn}$ recovery as the objective function can be obtained: $y=88.76+8.05 x_{1}+1.32 x_{2}+0.52 x_{3}+1.13 x_{1} x_{2}+0.71 x_{1} x_{3}-1.24 x_{2} x_{3}-5.36 x_{1}^{2}-3.00 x_{2}^{2}-2.92 x_{3}^{2}$

The validity of mathematical model is analyzed and tested, and the results are shown in table 5.

Table 5 Variance analysis of regression equation on zinc recovery

\begin{tabular}{cccccc}
\hline Source & Sum of squares & $\begin{array}{c}\text { Degree of } \\
\text { freedom }\end{array}$ & Mean square & F value & P value \\
\hline Model & 763.01 & 9 & 84.78 & 10.17 & 0.0029 \\
$\mathrm{x}_{1}$ & 518.90 & 1 & 518.90 & 62.24 & $<0.0001$ \\
$\mathrm{x}_{2}$ & 13.91 & 1 & 13.91 & 1.67 & 0.2374 \\
$\mathrm{x}_{3}$ & 2.16 & 1 & 2.16 & 0.26 & 0.6262 \\
$\mathrm{x}_{1} \mathrm{x}_{2}$ & 5.09 & 1 & 5.09 & 0.61 & 0.4604 \\
$\mathrm{x}_{1} \mathrm{x}_{3}$ & 2.02 & 1 & 2.02 & 0.24 & 0.6379 \\
$\mathrm{x}_{2} \mathrm{x}_{3}$ & 6.15 & 1 & 6.15 & 0.74 & 0.4188 \\
$\mathrm{x}_{1}^{2}$ & 120.80 & 1 & 120.80 & 14.49 & 0.0067 \\
$\mathrm{x}_{2}^{2}$ & 37.80 & 1 & 37.80 & 4.53 & 0.0707 \\
$\mathrm{x}_{3}^{2}$ & 35.99 & 1 & 35.99 & 4.32 & 0.0763 \\
Residual & 58.36 & 7 & 8.34 & & \\
Pure error & 0.00 & 4 & 0.00 & & \\
Total deviation & 821.37 & 16 & & & \\
\hline
\end{tabular}

Notes: $\mathrm{P}<0.001$ is extremely significant difference, $\mathrm{P}<0.01$ is highly significant difference, $\mathrm{P}<0.05$ is significant difference. 
According to the results of table 5, it can be known that the model is highly significant and test error is very small. Table 5 also illustrates the concentration of sodium sulfide has great influence to the recovery of $\mathrm{Zn}$ concentrate.

\subsection{Response surface analysis and optimization}

The results are shown in Fig. 1 in terms of the response surface plot on Zn recovery in the condition of varying $\mathrm{Na}_{2} \mathrm{~S}$ concentration and $\mathrm{F} 1$ concentration when $\mathrm{Na}_{2} \mathrm{CO}_{3}$ concentration is $2000 \mathrm{~g} / \mathrm{t}$. As can be seen from the plot in Fig.1, the $\mathrm{Zn}$ recovery raises the maximum and then decreases slightly along with increasing $\mathrm{Na}_{2} \mathrm{~S}$ concentration and $\mathrm{F} 1$ concentration at the same time. Zn recovery did not change as increasing $\mathrm{F} 1$ concentration at low $\mathrm{Na}_{2} \mathrm{~S}$ concentration. Zn recovery first increases and then decreases when increases F1 concentration in the condition of high $\mathrm{Na}_{2} \mathrm{~S}$ concentration. Fig.2 illustrates the response surface plot on $\mathrm{Zn}$ recovery as a function of the different $\mathrm{Na}_{2} \mathrm{~S}$ concentration and $\mathrm{Na}_{2} \mathrm{CO}_{3}$ concentration. The $\mathrm{Zn}$ recovery can reach the maximum along with increasing $\mathrm{Na}_{2} \mathrm{~S}$ concentration when F1 concentration is $750 \mathrm{~g} / \mathrm{t}$ and $\mathrm{Na}_{2} \mathrm{CO}_{3}$ concentration is $2000 \mathrm{~g} / \mathrm{t}$. Zn recovery shows a trend of decline when $\mathrm{Na}_{2} \mathrm{CO}_{3}$ concentration is more than $2000 \mathrm{~g} / \mathrm{t}$.

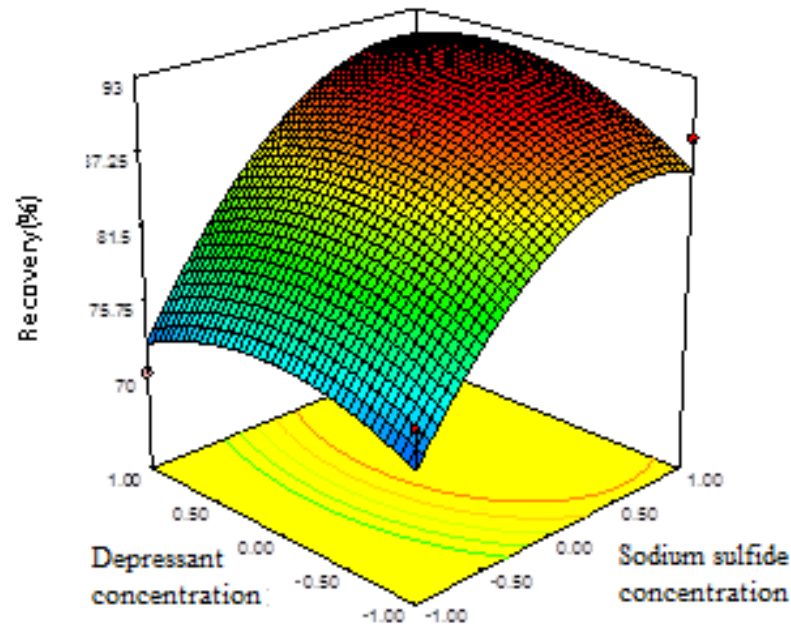

Fig 1

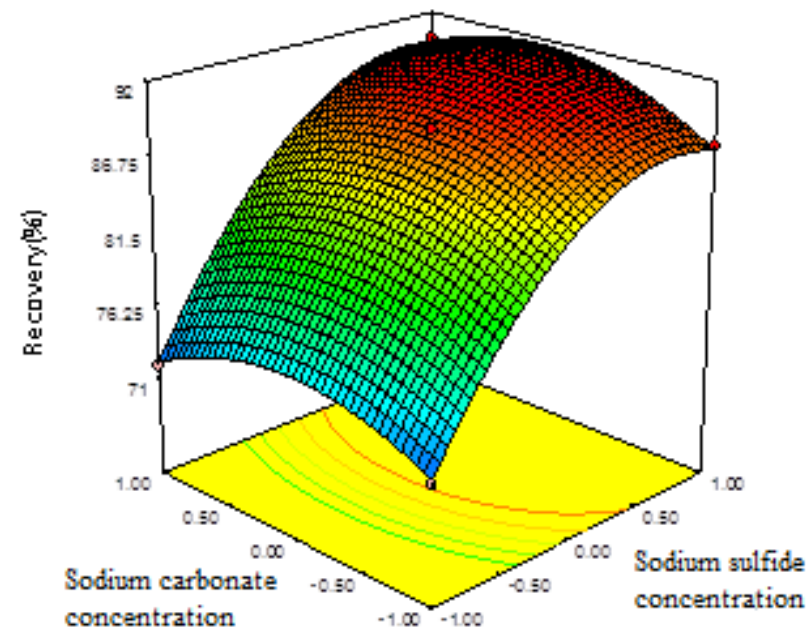

Fig 2

Fig1 Response surface plot for the effects of sodium sulfide concentration and depressant concentration on $\mathrm{Zn}$ recovery

Fig2 Response surface plot for the effects of sodium sulfide concentration and sodium carbonate concentration on Zn recovery

In order to determine the value of the optimal point, the quadratic multivariate regression equation of taking $\mathrm{Zn}$ recovery as the objective function was solved first order partial derivative, and making it equal to zero. The following set of equations can be got.

$$
\begin{array}{r}
-10.72 x_{1}+1.13 x_{2}+0.71 x_{3}=-8.05 \\
1.13 x_{1}-6 x_{2}-1.24 x_{3}=-1.32 \\
0.71 x_{1}-1.24 x_{2}-5.84 x_{3}=-0.52
\end{array}
$$

To solve the equation group 1.2: $\mathrm{x}_{1}=0.79, \mathrm{x}_{2}=0.35, \mathrm{x}_{3}=0.11$, that is the optimal level value of the three factors. After transforming, the highest $\mathrm{Zn}$ recovery $92.22 \%$ can be gained when $\mathrm{Na}_{2} \mathrm{~S}$ concentration is $7685 \mathrm{~g} / \mathrm{t}$, F1 concentration is $1012.5 \mathrm{~g} / \mathrm{t}$, and $\mathrm{Na}_{2} \mathrm{CO}_{3}$ concentration is $2220 \mathrm{~g} / \mathrm{t}$. 


\subsection{Verification test}

In order to test the reliability of the results obtained by the response surface method, three sets of parallel verification tests were conducted under the conditions of the selected conditions $\left(\mathrm{Na}_{2} \mathrm{~S}\right.$ concentration is $7500 \mathrm{~g} / \mathrm{t}$, F1 concentration is $1050 \mathrm{~g} / \mathrm{t}$, and $\mathrm{Na}_{2} \mathrm{CO}_{3}$ concentration is $2200 \mathrm{~g} / \mathrm{t}$ ). The results show that the average $\mathrm{Zn}$ recovery is $91.08 \%$. So we can know that the theory predicted value of the Zn recovery is very close to the experimental value and the error is only $1.14 \%$. Therefore, the optimal parameters of flotation process are accurate and reliable based on the response surface method, which has practical value.

\section{Conclusions}

(1) The Zn content in the original zinc oxide sample used in the study is $7.45 \%$, and the contents of major zinc phase such as carbonate zinc, silicate zinc and sulfide zinc are 3.75\%, 3.14\% and 0.48\%, respectively. It should be noted that the oxidation rate of the sample reaches as high as $93.56 \%$, and there are $42.15 \%$ silicate zinc, which confirms that the sample is refractory zinc oxide ore of low grade.

(2) According to the results of variance analysis of quadratic multivariate regression equation on zinc recovery, it can be known that the model is highly significant and test error is very small, and the concentration of sodium sulfide has great influence to the recovery of $\mathrm{Zn}$ concentrate.

(3) The regression model between Zn recovery and sodium sulfide concentration, depressant concentration and sodium carbonate concentration was established. The verification tests results show that the model is reliable and can predict accurately the zinc recovery. It can be known that the optimizing process parameters are sodium sulfide $7500 \mathrm{~g} / \mathrm{t}$, depressant(F1) concentration 1050g/t, and sodium carbonate concentration $2200 \mathrm{~g} / \mathrm{t}$.

\section{Acknowledgements}

This work is financially supported by the Yunnan Natural Science Foundation of China (Grant No. 2012FB198) and the Yunnan Province Technology Innovation Talents Cultivation Object (Grant No. 2014HB074). The authors also would like to acknowledge the colleagues attended the experiment, which helps us to overcome some initial obstacles and misunderstandings in experimental research.

\section{References}

[1] S.H.Hosseini, Eric Forssberg, Physicochemical studies of smithsonite flotation using mixed anionic/cationic collector, Minerals Engineering, 20(2007):621-624

[2] Li Mingxiao, New process of dressing-metallurgy combination with refractory zinc oxide ore of low grade based on circular economy, PhD Thesis of Kunming University of Science and Technology, 2011 [in chinese]

[3] G.onal, G.Bulut, A.Gul, et al, Flotation of Aladag oxide lead-zinc ores, Minerals Engineering, 18 (2005):279-282

[4] M. Irannajad, M. Ejtemaei, M. Gharabaghi, The effect of reagents on selective flotation of smithsonite-calcite-quartz, Minerals Engineering, 22 (2009):766-771

[5] Liu Shuang, Sun Chunbao, Chen Xiuzhi, The effect of $\mathrm{Ca}^{2+}, \mathrm{Mg}^{2+}$ and $\mathrm{SO}_{4}{ }^{2-}$ on flotation of Huize $\mathrm{Pb}-Z n$ sulfide ores, Non-ferrous Metal(beneficiation part), 2 (2007) 26-28[in chinese]

[6] A.H. Navidi Kashani, F. Rashchi, Separation of oxidized zinc minerals from tailings: Influence of flotation reagents, Minerals Engineering, 21 (2008) 967-972 